\title{
Tax rates as strategic substitutes
}

\author{
Hendrik Vrijburg • Ruud A. de Mooij
}

Published online: 27 December 2014

(C) Springer Science+Business Media New York 2014

\begin{abstract}
This paper analytically derives conditions under which the slope of the tax-reaction function is negative in a classical tax competition model. If countries maximize welfare, a negative slope (reflecting strategic substitutability) occurs under relatively mild conditions. The strategic tax response is crucial for understanding tax competition games, as well as the welfare effects of partial tax unions (whereby a subset of countries coordinate their tax rates). Indeed, contrary to earlier findings that have assumed strategic complementarity in tax rates, we show that partial tax unions might reduce welfare under strategic substitutability.
\end{abstract}

Keywords Strategic substitutes - Asymmetry - Strategic tax response · Tax coordination

JEL Classification $\quad \mathrm{E} 62 \cdot \mathrm{F} 21 \cdot \mathrm{H} 25 \cdot \mathrm{H} 77$

\section{Introduction}

Most of the tax competition literature impose that tax rates are strategic complements, i.e. if one country increases its tax rate, the best response of the other countries is to

Views are those of the authors and should not be attributed to IMF or IMF policy.

H. Vrijburg $(\bowtie)$

Erasmus School of Economics, Tinbergen Institute, Erasmus University Rotterdam, P.O. Box 1738, 3000 DR Rotterdam, The Netherlands e-mail: vrijburg@ese.eur.nl

R. A. de Mooij

International Monetary Fund, Washington, DC, USA

e-mail:RDeMooij@imf.org 
also increase their rate. This, however, is based on specific modeling assumptions. For instance, a negatively sloped tax-reaction function (i.e. strategic substitutes) is ruled out if governments maximize tax revenues rather than welfare (as in e.g. Kanbur and Keen 1993) or if a linear utility function is adopted in which public goods are at the margin valued more than private goods (as in e.g. Devereux et al. 2008; Bucovetsky 2009). The presumption that tax rates are strategic complements is not always supported by empirical studies, however. In particular, several recent studies estimate tax-reaction functions by regressing the tax of countries or local governments on some weighted average of the tax in other jurisdictions. Thus, Devereux et al. (2008) and Overesch and Rincke (2011) find that, on average, statutory corporate tax rates in OECD countries are strategic complements. ${ }^{1}$ Yet, several studies report evidence for a negatively sloped tax-reaction function, i.e. they report a negative coefficient for the tax rate in other jurisdictions. Indeed, this is found for effective tax rates on capital income (Leibrecht and Hochgatterer 2012), for tax competition between US States (Chirinko and Wilson 2011) and for personal income taxes in local jurisdictions in Switzerland (Parchet 2013). Moreover, even if the average best response is positive, some countries may still respond in an opposite manner.

This paper explores the possibilities for tax rates to be strategic substitutes. In particular, it adopts a classical tax competition model with a flexible objective function for the government to derive conditions under which the slope of the tax-reaction function can be negative. These conditions turn out to be rather mild and hold for plausible parameter configurations. Hence, strategic substitutability should not be ruled out, as previous studies have done.

The slope of the tax-reaction function can have important implications for the analysis of tax competition and tax coordination, such as the welfare effects of a tax union, whereby some countries opt in and others opt out of a tax agreement. In Konrad and Schjelderup (1999), for example, the tax union is found to be unambiguously welfare improving if tax rates are strategic complements. However, as we will show below, the union countries may no longer benefit from such a tax union if tax rates are strategic substitutes.

Only few papers in the literature allow tax rates to be strategic substitutes, and even fewer study it in greater detail. ${ }^{2}$ Mintz and Tulkens (1986) explore commodity tax competition between regions and-although their paper does not focus on strategic tax responses-note that 'strategic substitutes follows when a sufficient degree of inelasticity of the demand for the public good prevails [p. 154]'. Wilson (1991) makes a brief remark about the slope of the reaction function in a footnote, saying that it depends on the utility function and 'hardto-interpret' properties like third derivatives of the production functions (Wilson 1991, p. 440, footnote 13). Laussel and Le Breton (1998) study the existence

\footnotetext{
1 Apart from tax-reaction functions for corporate taxes, the literature has also studied tax-reaction functions for consumption taxes (Egger et al. 2005a, b; Jacobs et al. 2010) and public expenditures (Case et al. 1993). See Brueckner (2003) for an overview of empirical studies.

2 The industrial organization literature has paid more attention to the slope of reaction functions; see e.g. Bulow et al. (1985) for a classical reference on the discussion of strategic complements and substitutes, applied to industrial organization.
} 
of Nash-equilibria in tax competition models and also mention that tax-reaction curves can be non-linear (concave). Brueckner and Saavedra (2001) show that strategic substitutes can occur when governments maximize a linear utility function, where the marginal value of private goods exceeds that of public goods (in contrast to Devereux et al. 2008; Bucovetsky 2009, where public goods are valued more at the margin). In Chirinko and Wilson (2011), tax rates can be strategic substitutes under an addilog utility function in which public and private goods are separable (see Houthakker 1960 for a discussion of this utility function). The slope of the tax-reaction function in their model depends on the income elasticity of demand for private relative to public goods. For a homothetic utility function, they find that the slope of the reaction function is flat (p. 11).

Our paper deviates from these earlier papers in three major ways. First, we analytically derive the conditions under which tax rates are strategic substitutes using a more flexible CES utility function, comprising public and private goods. The results are based on linearizations of the model, and hold only locally in the neighborhood of the initial equilibrium. They are related to Chirinko and Wilson (2011), although based on a more general utility function than theirs, which yields markedly different interpretations. In particular, the slope of the tax-reaction function in our model depends crucially on the substitution elasticity between public and private goods. Intuitively, a higher foreign tax rate creates an inflow of capital to the own country, which raises public income if the existing capital income tax is positive. For low values of the substitution elasticity, the optimal response for the government is to reduce the tax rate so as to increase private consumption. Thus, our intuition is closer to that in Mintz and Tulkens (1986), although our model considers capital income taxes, rather than consumption taxes. A second contribution of the paper is that it illustrates the global properties of tax-reaction function by using simulations. For various plausible parameter figurations, it shows that tax-reaction functions can be negatively sloped. Finally, the paper shows the importance of the slope of the taxreaction function for the welfare analysis of tax coordination. In particular, countries that form a tax union may suffer a welfare loss from coordinating their tax rates if the best response of outsider countries is to do the opposite from the union countries. Hence, we find that tax unions are less likely if tax rates are strategic substitutes.

The rest of the paper is organized as follows. Section 2 introduces the model. Section 3 derives linearized tax-reaction function analytically and discusses conditions for tax rates to be strategic substitutes around an initial equilibrium. Section 4 numerically simulates tax-reaction function, showing their global properties for specific parameter configurations. Section 5 illustrates the importance of strategic tax responses for the welfare effects from the formation of tax unions. Section 6 concludes.

\section{A model of tax competition}

Consider $n \geq 2$ countries, that are potentially asymmetric. We use $i, j \in\{1, \ldots, n\}$ with $i \neq j$ as country indices. Country $i$ is populated by a fixed number of $N_{i}$ 
immobile households. Population size relative to world population $(N)$ will be denoted by $s_{i}=N_{i} / N$. Each household in country i has a capital endowment $\left(e_{i}\right)$ and a labor endowment $(l=1)$, which they supply inelastically. Hence, labor constitutes a fixed factor in production. Capital is perfectly mobile internationally. ${ }^{3}$

\subsection{Firms and capital market equilibrium}

A representative firm in each country produces a single good using a stock of capital $\left(K_{i}\right)$ and effort from labor $\left(N_{i}\right)$. There is perfect competition in the output market. In each country, the production function $F\left(K_{i}, N_{i}\right)$ is homogeneous of degree one, so it can be written in intensive form: $N_{i} f\left(k_{i}\right)$ where $k_{i}=K_{i} / N_{i}$ denotes the capital-labor ratio employed in country $i . F($.) is concave in its two inputs and twice continuously differentiable. Hence: $f^{\prime}\left(k_{i}\right)>0, f^{\prime \prime}\left(k_{i}\right)<0$. Profit maximizing firms set the marginal product of capital equal to its price: the tax-inclusive cost of capital. Firms face a distortionary source-based unit-specific tax on capital $\left(t_{i}\right){ }^{4}$

The first-order condition for profit maximization yields for all $i$

$$
f_{i}^{\prime}\left(k_{i}\right)=t_{i}+\rho
$$

The after-tax rate-of-return on capital $(\rho)$ is equal across countries due to the international mobility of capital. That is, $\rho$ is endogenously determined on the world's capital market such that Eq. (1) hold and the resource constraint

$$
\sum_{i=1}^{n} s_{i} e_{i}=\sum_{i=1}^{n} s_{i} k_{i} \equiv \frac{K}{N}
$$

is satisfied, where $K$ denotes the fixed world's capital stock. ${ }^{5}$ An increase in the tax rate of country $i\left(t_{i}\right)$ reduces the capital stock in country $i$

$$
\frac{\partial k_{i}}{\partial t_{i}}=\frac{1}{f_{i}^{\prime \prime}(.)}\left[1+\frac{\partial \rho}{\partial t_{i}}\right]<0,
$$

\footnotetext{
${ }^{3}$ Our results do not rely on these assumptions, but on an endogenous marginal rate of substitution between public and private goods and a government that can only use source-based taxes on capital. See e.g. Bucovetsky and Wilson (1991) who show that in case households supply both capital and labor endogenously, a similar Nash-equilibrium exists when residence-based taxes are ruled out.

${ }^{4}$ Lockwood (2004) studies the case for an ad-valorem tax rate. Results are comparable, although taxcompetition is more intense under ad-valorem tax rates as price changes magnify the impact of taxes. This does not affect our results though.

5 We assume (and make sure in our simulation analysis) that $\rho>0$, ruling out the possibility that part of the capital stock is not used.
} 
which is obtained by partially differentiating Eq. (1), holding constant $t_{j}$ for $j \neq i$. Equation (3) can be signed using $f_{i}^{\prime \prime}()<$.0 and the sign of the final term ${ }^{6}$

$$
-1<\frac{\partial \rho}{\partial t_{i}}=\frac{-s_{i}\left(1 / f_{i}^{\prime \prime}(.)\right)}{\sum_{j=1}^{n} s_{j}\left(1 / f_{j}^{\prime \prime}(.)\right)}<0 .
$$

When all countries are small relative to the capital market, then we have $\partial \rho / \partial t_{i} \approx 0$. This case is studied in Zodrow and Mieszkowski (1986) and Wilson (1986). However, $\rho$ unambiguously decreases with $t_{i}$ if the number of countries is small and at least some countries are large compared to the world's capital market (see e.g. Wildasin 1989; Bucovetsky 1991; Wilson 1991). An increase in $t_{i}$ lowers the net marginal product in country $i$ and causes capital to relocate towards the remaining countries. If the capital flow is large compared to the world's capital market, this reduces the marginal product of capital abroad. The larger country $i$ is relative to the world's capital market, the stronger its market power and the larger is this effect.

\subsection{Consumers}

A representative consumer features a twice-continuously differentiable, monotonously increasing utility function of the form: $U_{i}\left(g_{i}, c_{i}\right)$, where $g_{i}$ and $c_{i}$ denote, respectively public and private consumption. Household private consumption is subject to a household budget constraint, given by

$$
c_{i}=\left[f_{i}(.)-f_{i}^{\prime}(.) k_{i}\right]+\rho e_{i} .
$$

Hence, private consumption equals the return to labor (the wage), given by the term in between square brackets on the right-hand side of Eq. (5), plus interest income from the capital endowment $\left(\rho e_{i}\right)$.

\subsection{Government}

The government maximizes welfare, which is determined by the utility of the representative household, by choosing the tax rate $t_{i}$. Thereby, it takes the government budget constraint into account, which restricts public consumption to tax revenues

$$
g_{i}=t_{i} k_{i}
$$

and the tax rates decided on by the government of other countries: $t_{j}$ for all $j \neq i$. This latter assumption implies that we study Nash-equilibria. For each country, the

\footnotetext{
$\overline{6 \text { See the Appendix for a derivation. }}$
} 
optimum satisfies the following condition

$$
\frac{\partial U_{i} / \partial t_{i}}{u_{c, i}}=\left[\frac{\partial c_{i}}{\partial t_{i}}\right]+\frac{u_{g, i}}{u_{c, i}}\left[\frac{\partial g_{i}}{\partial t_{i}}\right]=0,
$$

where $u_{g, i} / u_{c, i}>0$ is short-hand notation for $u_{g, i}\left(c_{i}, g_{i}\right) / u_{c, i}\left(c_{i}, g_{i}\right)$ denoting the marginal rate of substitution (MRS) between public and private goods. The right-hand side of Eq. (7) measures the welfare effect of the tax via, respectively, changes in private consumption and public consumption, which are obtained by taking the partial derivatives of (5) and (6)

$$
\begin{aligned}
& \frac{\partial c_{i}}{\partial t_{i}}=-f_{i}^{\prime \prime}(.) \frac{\partial k_{i}}{\partial t_{i}} k_{i}+\frac{\partial \rho}{\partial t_{i}} e_{i}<0, \\
& \frac{\partial g_{i}}{\partial t_{i}}=k_{i}\left[1+\frac{t_{i}}{k_{i}} \frac{\partial k_{i}}{\partial t_{i}}\right]>0 .
\end{aligned}
$$

Equation (8) shows that a higher tax rate reduces private consumption for two reasons. First, a higher tax will cause an outflow of capital. The smaller capital stock reduces labor productivity and, therefore, the wage and private consumption. Second, the higher tax reduces the world's net-of-tax return on capital and, therefore, interest income. This magnifies the reduction in private consumption.

Equation (9) shows that the effect of a higher tax on public consumption depends on where we are on the Laffer curve. The first term on the right-hand side of Eq. (9) shows that a higher tax raises revenue over the existing tax base. The second term indicates that a higher tax causes an erosion of the tax base to the extent that it reduces the domestic capital stock. This reduces tax revenue, especially when the initial tax rate is high. From Eqs. (8) and (7), it follows that a utility maximizing tax rate requires that Eq. (9) is positive. That is, the utility maximizing tax rate is always on the upward sloping part of the Laffer curve.

Now define $\eta_{k, i} \equiv-\frac{\partial k_{i}}{\partial t_{i}} \geq 0$ as minus the tax coefficient of capital and $\eta_{r, i} \equiv$ $-\frac{\partial \rho}{\partial t_{i}} \geq 0$ as minus the tax coefficient of the interest rate. Together with Eqs. (8), (9) and (3), we can rewrite Eq. (7) as

$$
\frac{u_{g, i}}{u_{c, i}}=\frac{k_{i}+\eta_{r, i}\left[e_{i}-k_{i}\right]}{k_{i}-t_{i} \eta_{k, i}} \equiv \mathrm{MCF},
$$

reflecting the modified Samuelson rule. It shows that the marginal rate of substitution between public and private goods on the left-hand side is equal to the marginal cost of public funds (henceforth MCF) times the marginal rate of transformation (which equals unity in our model). Equation (10) shows that the MCF rises in the tax coefficient of capital $\eta_{k, i}$ as this increases the erosion of the tax base induced by the tax. Furthermore, the MCF in Eq. (10) increases in $\eta_{r, i}$ if country $i$ is a net capital exporter $\left(e_{i}>k_{i}\right)$. It decreases if it is a net capital importer $\left(e_{i}<k_{i}\right)$. Intuitively, a net capital exporter is a net receiver of interest vis-a-vis the rest of the world. Therefore, it suffers from a welfare loss if the interest rate drops. This makes public goods more expensive as higher taxes reduce the interest rate. This implies that for capital exporting countries 
we unambiguously have $u_{g, i} / u_{c, i}=\mathrm{MCF}>1$. This is the standard tax competition result: the public good is undersupplied due to positive spillovers from taxation. For a net capital importer, the lower interest rate is a net benefit because the country pays less to foreign capital owners. This reduces the MCF. In principle, this might even cause $u_{g, i} / u_{c, i}=\mathrm{MCF}_{i}<1$, implying that the public good is oversupplied.

\subsection{Equilibrium}

Equilibrium is defined as a set of Nash-equilibrium tax rates ( $t_{i}$ for all $i$ ), capital stocks $\left(k_{i}\right.$ for all $i$ ) and an interest rate $\rho$ that simultaneously satisfy for each country both the modified Samuelson rule in Eq. (10) and the demand for capital in Eq. (1), and for all countries together the world resource constraint. ${ }^{7}$ In the Nash-equilibrium we need that every country chooses the tax rate optimal given the tax rates decided on by other governments. This requires that for all countries, the second-order condition for a welfare maximum is negative

$$
\frac{\partial u_{g, i} / u_{c, i}}{\partial t_{i}}-\frac{\partial \mathrm{MCF}_{i}}{\partial t_{i}}<0 .
$$

given the tax rates of the other countries.

With respect to the first term, we follow e.g. Bucovetsky (1991) and Taugourdeau and Ziad (2011) by assuming that both $g_{i}$ and $c_{i}$ are normal goods. Together with the tax being on the upward-sloping part of the Laffer curve [which follows from the signs of Eqs. (7)-(9)], this implies that: $\partial\left(u_{g, i} / u_{c, i}\right) / \partial t_{i} \leq 0$, i.e. choosing a higher tax rate leads to a reduction in the marginal valuation of the public good.

The difficulty lies in proving that $\partial \mathrm{MCF}_{i} / \partial t_{i}>0$. Bucovetsky (1991) shows that this is the case for a quadratic production function, which has subsequently been used by e.g. Bucovetsky (2009) and Devereux et al. (2008) (while Parry 2003 assumes that $\partial k_{i} / \partial t_{i}$ is linear in the relevant range). This assumption ensures that the tax base elasticity $\left(\epsilon_{k, i}=\left(\partial k_{i} / \partial t_{i}\right)\left(t_{i} / k_{i}\right)\right)$ is unambiguously decreasing in the capital stock and that the Laffer curve of country $i$ is unambiguously shifted outwards if capital flows in. In the next section, we will also use the quadratic production function to avoid complications. ${ }^{8}$

\footnotetext{
${ }^{7}$ Some papers have proven the existence of a Nash-equilibrium in models more stylized than ours, see e.g. Laussel and Le Breton (1998) and Bayindir-Upmann and Ziad (2005), but for the model used here existence has not yet been proven.

${ }^{8}$ For a more general production function, Taugourdeau and Ziad (2011) show that a second-order locally consistent equilibrium exists in case of a positive third derivative of the production function and the prescription that the demand for capital should not be increasing in capital $\left(\partial \ln f_{i}^{\prime} / \partial \ln k_{i} \leq 0\right)$. These conditions hold for a wide range of production functions commonly used in the economic literature, such as: CobbDouglas; Quadratic; Logarithmic; Exponential; Logistic; and a CES production function in case the capital share in production, and/or the substitution elasticity between capital and the fixed factor, are not too large in the CES production. The result in Taugourdeau and Ziad (2011) does require that all capital is owned by individuals living outside the countries considered $\left(e_{i}=0\right)$.
} 


\section{Strategic tax responses}

We now explore the slope of the tax-reaction function. If the slope is positive, then a tax increase abroad will induce a country to also increase its own tax rate and we speak of 'strategic complements'. If the slope is negative, then a higher tax abroad will trigger a decrease in the country's own tax rate as a response and we refer to this as 'strategic substitutes'.

In general, tax-reaction functions take the form: $t_{i}=V_{i}\left(t_{j}, t_{-j}\right)$, where $V_{i}\left(t_{j}, t_{-j}\right)$ gives the best response of country $i$ to the tax rates chosen by country $j$ and all remaining countries (where we denote the set of all countries not including countries $i$ and $j$ by $-j$ ). Because there are no closed form expressions for the tax rates in general, we linearize the tax-reaction function around an initial equilibrium. This yields analytical expressions for the tax change by country $i$ in response to tax changes in (one of) the other countries. The linearized tax responses reflect optimal marginal tax responses, evaluated at an initial equilibrium, to an assumed exogenous marginal change in the tax rate of country $j$ (which might represent a group of countries that uniformly raise their tax). Hence, the analytical results derived will hold locally in the neighborhood of the equilibrium. Section B in the online Appendix derives the linearized tax-reaction functions by linearizing Eq. (10) around an initial equilibrium, while assuming a CES utility function and a quadratic production function: $f(k)=$ $b(a-k) k .{ }^{9}$ When we denote a percentage change in variable $x$ as: $\partial x / x=\partial \ln (x)=\tilde{x}$, the reaction function is given by

$$
\tilde{t}_{i}=\frac{\left[\left(\frac{1}{1-\epsilon_{k, i}}+\frac{\eta_{r, i}-1}{\gamma_{i}}\right)-\frac{1}{\sigma_{i}} \phi_{i}\right] \epsilon_{k, j}^{\prime}}{\left(\frac{2}{1-\epsilon_{k, i}}+\frac{\eta_{r, i}-1}{\gamma_{i}}\right) \epsilon_{k, i}+\frac{1}{\sigma_{i}}\left(1+\frac{e_{i} t_{i}}{c_{i}}-\phi_{i} \epsilon_{k, i}\right)} \tilde{t}_{j},
$$

where $\sigma_{i} \equiv d \log \left(c_{i} / g_{i}\right) / d \log \left(\mathrm{MRS}_{i}\right)>0$ denotes the elasticity of substitution between public and private goods. If $\sigma_{i}$ is large, public and private goods are close substitutes, so that the MRS is not strongly affected by changes in the ratio of privateto-public consumption. In the limit $\sigma \rightarrow \infty$ we approach a constant MRS. With respect to the other parameters, $0<\epsilon_{k, i} \equiv t_{i} \eta_{k, i} / k_{i} \leq 1$ denotes the own capital stock elasticity, $\epsilon_{k, j}^{\prime} \equiv\left(\partial k_{i} / \partial t_{j}\right)\left(t_{j} / k_{i}\right)=-t_{j} /\left(k_{i} f_{i}^{\prime \prime}\right) \eta_{r, j}>0$ indicates a crosselasticity, $\gamma_{i} \equiv\left(-\partial c_{i} / \partial t_{i}\right) / k_{i}=1+\left(e_{i} / k_{i}-1\right) \eta_{r, i}$ reflects the reduction in private income following an increase in the own tax rate relative to the initial capital stock, and finally $\phi_{i} \equiv\left[-\partial \log \left(c_{i} / g_{i}\right) / \partial \log \left(t_{j}\right)\right] / \epsilon_{k, j}^{\prime}=\left[1+2 b \frac{e_{i}-k_{i}}{c_{i}} k_{i}\right]$ is proportional to the effect of a foreign tax increase on the private-to-public goods ratio. Note that from Eq. (10): $\mathrm{MCF}_{i}=\gamma_{i} /\left(1-\epsilon_{k, i}\right)$, such that $\gamma_{i}>0$ whenever $\mathrm{MCF}_{i}>0$. In a symmetric equilibrium $\left(e_{i}=k_{i}\right), \phi_{i}=\gamma_{i}=1$.

The denominator on the right-hand side of Eq. (11) is positive by assumption as it equals (minus) the second-order condition for a (local) welfare maximum for country $i$. Eq. (11) gives the marginal slope of the reaction function of country $i$ : if the coefficient

\footnotetext{
9 Besides deriving the linearized tax-reaction functions, Section B in the online Appendix also discusses how the slope of the reaction function changes for a CES production function. This complicates the analysis considerably but does not invalidate our main insights.
} 
on the right-hand side of (11) is positive, then tax rates are strategic complements; otherwise, they are strategic substitutes. Our focus will be on the prevalence of strategic substitutability, i.e. on cases under which the coefficient is negative. To interpret the slope coefficient, we discuss three special cases.

\subsection{Special case 1: constant MRS}

First, assume a constant MRS equal to $u_{g} / u_{c}$. This is the case when the utility function is linear (or $\sigma \rightarrow \infty$ ). This assumption is adopted by e.g. Devereux et al. (2008), and Bucovetsky (2009). Note that if $u_{g} / u_{c} \rightarrow \infty$, welfare maximization coincides with revenue maximization by the government, this is assumed by e.g. Kanbur and Keen (1993). When assuming a constant MRS, Eq. (11) reads as follows (where we use $\left.u_{g} / u_{c}=\gamma_{i} /\left(1-\epsilon_{k, i}\right)\right)$

$$
\tilde{t}_{i}=\frac{\left(\frac{u_{g}}{u_{c}}+\eta_{r, i}-1\right) \epsilon_{k, j}^{\prime}}{\left(2 \frac{u_{g}}{u_{c}}+\eta_{r, i}-1\right) \epsilon_{k, i}} \tilde{t}_{j} \text { for } i \neq j .
$$

We focus on the term in between brackets in the numerator. Using Eq. (10) we can derive the following condition

$$
\frac{u_{g}}{u_{c}}+\eta_{r, i}-1=\eta_{r, i} \frac{e_{i}}{k_{i}}+\frac{u_{g}}{u_{c}} \frac{t_{i}}{k_{i}} \eta_{k, i}>0,
$$

for $t_{i}>0, k_{i}>0$ and $e_{i}>0$. This leads to the following proposition

Proposition 1 In case of a constant MRS, the tax-reaction function is always positively sloped: tax rates are strategic complements. The slope of the reaction function is steeper, the larger is the marginal valuation of public goods relative to private goods $\left(u_{g} / u_{c}\right)$.

See Mintz and Tulkens (1986, p. 153) who claim a similar result for revenue maximizers in their commodity tax competition model. To understand Eq. (12), note that a higher tax in country $j$ will cause an inflow of capital to country $i$, which is measured by $\epsilon_{k, j}^{\prime}>0$. This boosts both private consumption, due to a positive impact of the capital inflow on the wage rate, and public consumption as the broadening of the domestic tax base raises public revenue if the tax rate is kept unchanged. The optimal response in the tax rate depends on how consumers value public and private consumption. The term $u_{g} / u_{c}-1$ measures the extent to which the MRS between public and private goods exceeds the marginal rate of transformation (MRT). According to the modified Samuelson rule in Eq. (10), this occurs if the MCF exceeds unity in which case public goods are scarcer than private goods due to distortionary taxation. Ignoring the term $\eta_{r, i}$, Eq. (12) suggests that this would make it optimal for the government to raise public goods supply. Intuitively, the exogenous inflow of capital on account of the 
higher tax rate abroad reduces the MCF, making it less costly to supply public goods and allowing for a higher tax rate. Accordingly, tax rates are strategic complements. ${ }^{10}$

The tax response depends also on the impact of the change in $t_{i}$ on the interest rate, which is measured by $\eta_{r, i}$. The extra inflow of capital as a result of a higher foreign tax rate is cheaper if the interest rate that needs to be paid to foreign capital owners is lower. As an increase in the domestic tax rate indeed reduces the interest rate by $\eta_{r, i}$, this encourages country $i$ to increase its domestic tax rate. This channel critically depends on country size, however. Indeed, when $n \rightarrow \infty$ or if country $i$ is very small relative to the rest of the world, this channel becomes irrelevant, i.e. $\eta_{r, i}$ is close to zero.

\subsection{Special case 2: symmetric countries}

The second special case is when the MRS is no longer constant, but countries are symmetric. This implies $s_{i}=1 / n, e_{i}=k_{i}=e, U_{i}(c, g)=U(c, g)$ for given $c, g$ and all $i \in\{1: n\}$. Also note that, $\gamma_{i}=\phi_{i}=1$, such that $u_{g} / u_{c}=1 /\left(1-\epsilon_{k, i}\right)$. The marginal slope of the reaction function is now given by

$$
\tilde{t}_{i}=\frac{\left(\frac{u_{g}}{u_{c}}+\eta_{r, i}-1-\frac{1}{\sigma_{i}}\right) \epsilon_{k, j}^{\prime}}{\left(2 \frac{u_{g}}{u_{c}}+\eta_{r, i}-1-\frac{1}{\sigma_{i}}\right) \epsilon_{k, i}+\left(1+\frac{g}{c}\right) \frac{1}{\sigma_{i}}} \tilde{t}_{j} .
$$

As the denominator is positive by assumption, the slope of the reaction function in Eq. (14) is determined by the sign of the numerator, which besides the term $\left(u_{g} / u_{c}+\right.$ $\left.\eta_{r, i}-1\right)$ that also features in Eq. (12) depends on the substitution elasticity between public goods and private consumption $(\sigma)$. This leads to the following proposition

Proposition 2 With symmetric countries, the slope of the tax-reaction function will be negative (strategic substitutes) when $\sigma_{i}<\bar{\sigma} \equiv 1 /\left[u_{g} / u_{c}-(n-1) / n\right]$.

Proposition 2 formalizes, for a CES utility function, the remark by Mintz and Tulkens (1986, p. 154) that 'strategic substitutes' follow when a sufficient degree of inelasticity of the demand for the public good prevails'. As noted before, the higher tax rate in country $j$ causes an inflow of capital in country $i$. The broader tax base raises public funds and yields more public goods. If public and private goods are close substitutes (a large value for $\sigma_{i}$ ), then there is little reason to reduce the tax rate in order to replace public by private consumption. However, if public and private goods are close complements (a small value for $\sigma_{i}$ ), then the government will find it optimal

\footnotetext{
10 Undersupply of the public good $\left(u_{g} / u_{c}>1\right)$ is a feature of standard tax competition models, where tax competition leads countries to choose inefficiently low tax rates (Zodrow and Mieszkowski 1986; Wilson 1986). The importance of $u_{g} / u_{c}>1$ was also stressed by Brueckner and Saavedra (2001), who argued that countries with a low valuation of public goods $\left(u_{g}<u_{c}\right)$ might feature a negatively sloped tax-reaction function, Eq. (13) shows that such a negative slope is ruled out in our model. The model of Brueckner and Saavedra is slightly more general, leading to a modified condition: $u_{g, i} / u_{c, i}+\eta_{r, i}-1=$ $\eta_{r, i}\left(e_{i} / k_{i}\right)+\left(u_{g, i} / u_{c, i}\right)\left(t_{i} / k_{i}\right) \eta_{k, i}+\left(q^{*} / k_{i}\right)\left(1-u_{g, i} / u_{c, i}\right)$ with $q^{*}$ denoting "land-endowment" per capita.
} 
to cut the tax rate so as to boost private consumption along with public consumption. This may cause tax rates to be strategic substitutes. Indeed, even if $u_{g} / u_{c}>1$, we could have a negatively sloped reaction curve if $\sigma_{i}$ is sufficiently small. ${ }^{11}$

The conditions for strategic substitutability hold under plausible parameter configurations. To illustrate this, assume that the MRS lies between 1.1 and 2, implying marginal excess burdens in the range between 0.1 and 0.5 . The number of countries is varied between 3 and 100 (note that $\partial \bar{\sigma} / \partial n>0$ in Proposition 2). For MRS $=2$ we obtain a value for $\bar{\sigma}$ equal to 0.75 when $n=3$, whereas it increases towards 1.00 for $n=100$. For MRS $=1.1$ we obtain a $\bar{\sigma}$ of 2.31 for $n=3$, while it increases to 10.00 when $n$ is 100 . Inversely, for $\sigma=1$, strategic substitutes will occur in a symmetric equilibrium whenever MRS $<\frac{2 n-1}{n}$. This is more likely when $n$ is larger. $^{12}$

\subsection{Special case 3: marginal change in capital endowment}

Equation (11) describes the marginal slope of the reaction function in the general case. General equilibrium effects and non-linearities in MRS and MCF make it impossible to draw unambiguous conclusions for this general case. Compared to the previous two special cases, the terms $\gamma_{i}$ and $\phi_{i}$ now appear in the marginal slope. Both parameters depend on net capital positions: for capital exporters $\left(e_{i}>k_{i}\right)$ we have $\gamma_{i}>1$ and $\phi_{i}>1$. Yet, being a capital exporter is endogenous. A net capital export position might be caused by country characteristics (fundamental parameters in the model) which simultaneously affect the different components of the initial equilibrium in Eq. (11) and, therefore, the prevalence of strategic substitutes. For example, bigger countries exert more power on international capital markets such that $\partial \eta_{r, i} / \partial s_{i}>0$, making strategic complementarity more likely for them. At the same time, bigger countries will set higher tax rates because they face a lower $\mathrm{MCF}$ (i.e. $\partial M C F / \partial s_{i}<0$ ). This makes them more likely to be capital exporters and, as long as $\sigma$ is small enough, makes strategic substitutability more likely. Also parameters in the utility function could simultaneously affect the ratio $u_{g} / u_{c}$ and the likelihood of being a capital exporter. As we will explain below, even if countries are symmetric except for the capital endowment $\left(e_{i}\right)$, general equilibrium effects cause $t_{i}, k_{i}, c_{i}$ and $g_{i}$ to differ between countries, with conflicting implications for the likelihood of strategic substitutes.

Given these complexities, we construct a special case to identify how the parameters $\gamma_{i}$ and $\phi_{i}$ affect the marginal slope of the reaction function in Eq. (11). For this, assume that countries are symmetric in population $(s=1 / n)$. We study the effect of a marginal increase in the capital endowment in one country, while leaving the total capital stock fixed: $\sum_{i=1}^{N} \partial e_{i}=0$. When studying the implications of such a perturbation for the reaction functions, we use the following lemma.

\footnotetext{
11 Closely related to this, Mintz and Tulkens (1986, p. 153) refer to the case where citizens demand a fixed level of public goods $(\bar{g})$. In that case, strategic substitutes always follow as an increase in the foreign tax rate allows a lower tax rate at home to achieve the same level of public revenues.

12 Using Eq. (10) under symmetry, this condition can be made more precise by relating it to the parameters of the model. However, we prefer to interpret the general condition as little intuition exists for the parameters in the stylized model and the tax rate that appears in the specific condition is endogenous.
} 
Lemma 1 With symmetric populations, there exists $a \sigma_{i} \equiv \hat{\sigma}$ for which $\partial t_{i} / \partial e_{i}=0$, such that $\partial k_{i} / \partial e_{i}=\partial \rho / \partial e_{i}=0$ for all $i \in N$. For a quadratic production function $f(k)=b(a-k) k$, and $a$ CES utility function: $\hat{\sigma} \equiv \frac{\rho}{c} n$.

Proof See Section C in the online Appendix.

For the tax rates to remain unchanged after a shock in $e_{i}$, we require an equivalent effect on $\mathrm{MCF}_{i}$ and $\mathrm{MRS}_{i}$. From Eq. (10) we find, $\partial \mathrm{MCF}_{i} / \partial e_{i}>0$. Hence, a larger capital endowment makes the tax more distortive because capital exporters, being net interest earners, experience a larger reduction in private consumption. $\partial \mathrm{MRS}_{i} / \partial e_{i}>0$ follows from Eqs. (5), (6) and the assumption that $c_{i}$ and $g_{i}$ are normal goods. Intuitively, a larger capital endowment makes, ceteris paribus, citizens of country $i$ richer, so that private consumption increases relative to public consumption. This increases the marginal valuation of public goods and induces the government to increase the tax. The strength of the change in the marginal valuation of public goods is determined by the substitution elasticity $\sigma_{i}$. Hence, there must exist a value for $\sigma_{i}$ for which the effects on $\mathrm{MCF}_{i}$ and $\mathrm{MRS}_{i}$ are equally strong and, hence, taxes are not affected by a marginal change in capital endowments. Symmetry ensures that this holds for all countries in case of a marginal change in $e_{i}$ (an increase for country $i$ and a reduction for all other countries). Given that none of the tax rates change, the equilibrium capital allocation does not change and the net interest rate remains constant. When $\sigma>\hat{\sigma}$ a higher capital endowment typically lowers the tax rate (see for example Peralta and van Ypersele 2005; Peralta and van Ypersele 2006, who study the extreme case with $\sigma \rightarrow \infty$ ), while for $\sigma<\hat{\sigma}$ it will increase the tax rate (a case that has not yet been studied in the literature). ${ }^{13}$

Using Lemma 1, we can define the following proposition that adheres to the final term in Eq. (11)

Proposition 3 With symmetric populations and $\sigma_{i}=\hat{\sigma}$ for all $i$, a marginal increase in $e_{i}$ unambiguously increases the likelihood that tax rates are strategic substitutes if $\hat{\sigma}<\check{\sigma} \equiv \frac{-f^{\prime \prime}}{c} n\left(\frac{n}{n-1}\right)$.

Proof See Section C in the online Appendix.

Hence, when $\hat{\sigma}<\check{\sigma}$ strategic substitutes is unambiguously more prevalent for capital exporters than for capital importers. We can numerically illustrate the condition in Proposition 3. For instance, for $n=3, t=0.5$ and $\mathrm{MCF}=3 / 2$, we find $\hat{\sigma}=1<$ ó. 14

The slope of the reaction function is generally determined by the change, caused by a foreign tax increase, in both the MCF and the MRS. Both are affected by the net capital position. Compared to the symmetric equilibrium, capital exporters face relatively high efficiency costs of taxation due to the effect of the tax on the country's own net interest income. The boost in the domestic tax base that follows a foreign

\footnotetext{
$13 \hat{\sigma} \rightarrow n$ when either $n$ or MCF increases. The range, $\sigma_{i} \in\{0, \hat{\sigma}\}$, in which an increase in the endowment of a country leads to an increase in the optimal tax $t_{i}$, is therefore relatively large. This contrasts with the cases studied in the literature.

14 For higher values of either $n$ or MCF; $\hat{\sigma} \rightarrow n$, whereas $\check{\sigma} \rightarrow 0$. As in such cases $\hat{\sigma}>\check{\sigma}$, strategic complementarity is more prevalent for capital exporters for higher values of $n$ or MCF while $\sigma_{i}=\hat{\sigma}$.
} 
tax increase, causes a relatively large reduction in the high MCF of a capital exporter. With respect to the marginal valuation of public goods, recognize that an increase in the foreign tax rate exerts a relative large decrease in private consumption of a capital exporting country, since it suffers more from the lower interest rate. This causes a larger reduction in the MRS for a capital exporter following a foreign tax increase. If $\sigma$ is small enough, the latter argument dominates the former and the government wants to lower its own tax rate in response to the foreign tax increase.

\section{Simulated tax-reaction functions}

While linearization offers insight in the parameters determining the slope of the taxreaction function, it offers only insight in the local, not in the global, properties of the tax-reaction function. This section illustrates the global properties of the tax-reaction function for a range of tax rates. That is, we not only focus on the equilibrium but also show the slope out of equilibrium. The simulations show that Propositions 1, 2 and 3 indeed continue to hold over this broader range of taxes, that is, the negative slope is not a phenomenon restricted to only the equilibrium values of the tax rates.

In performing the simulations, we make a number of assumptions. Throughout the exercises, we use a quadratic production function: $f(k)=b\left(a-k_{i}\right) k_{i}$ and assume three countries $(n=3)$. In the first simulation, countries are symmetric $(e=k=1)$ and of equal size $(s=1 / 3)$. This gives simple expressions for public and private consumption, as well as for the MCF: $c=b(a-1)-t ; g=t$ and MCF $=\frac{1}{1-t /(2 b)(2 / 3)}$. In the calibration, we set $t=1 / 2$ and $b=1 / 2$, implying that MCF $=3 / 2$. We adopt a CES utility function $U=\left(\omega c^{1-1 / \sigma}+(1-\omega) g^{1-1 / \sigma}\right)^{\sigma /(\sigma-1)}$, whereby we set $\omega=1 / 2$.

To satisfy the modified Samuelson rule, the symmetric equilibrium for a CES utility function yields

$$
(a-2)^{1 / \sigma}=3 / 2 \text {, }
$$

where we use $b=t=1 / 2$ and $u_{g} / u_{c}=(a-2)^{1 / \sigma}$.

Figures 1 and 2 show the tax-reaction curves for country $i$ together with the $45^{\circ}$ line (dotted). In Fig. 1 we vary $\sigma \in\{1,000,5,1,0.2\}$, while simultaneously adjusting $a$ to keep $u_{g} / u_{c}=3 / 2$ as described in Eq. (15). Wildasin (1989) and Parry (2003) study a range of $\sigma \in\{0.2: 1\}$ and $\sigma \in\{0.3: 1\}$, respectively, and stress that scarce empirical evidence points to an inelastic demand for public goods (see also Rubinfeld 1987). The point where the reaction function crosses the $45^{\circ}$ line represents the Nash-equilibrium in the case for symmetric countries. Figure 1 shows, consistent with Proposition 2, that the slope of the tax-reaction function is increasing in $\sigma$. For $\sigma=1,000$, we see that the reaction function is upward-sloping. Note that in this case the marginal rate of substitution is nearly constant, this is equivalent to assuming a linear objective function. The result therefore is consistent with Proposition $1 .{ }^{15}$ In case $\sigma=1$, the

\footnotetext{
15 By varying the value of $u_{g} / u_{c}$ underlying this simulation, the slope of the reaction function for $\sigma=1,000$ can be adjusted. Moreover, it is possible to obtain a slope of zero by choosing $u_{g} / u_{c}=2 / 3$. Indeed, for $s_{i}=1 / 3$ we have $\eta_{r, i}=1 / 3$ so that $u_{g} / u_{c}+\eta_{r, i}-1=0$. However, under the remaining parameter values, the equilibrium unit-specific tax rate is negative in this case.
} 


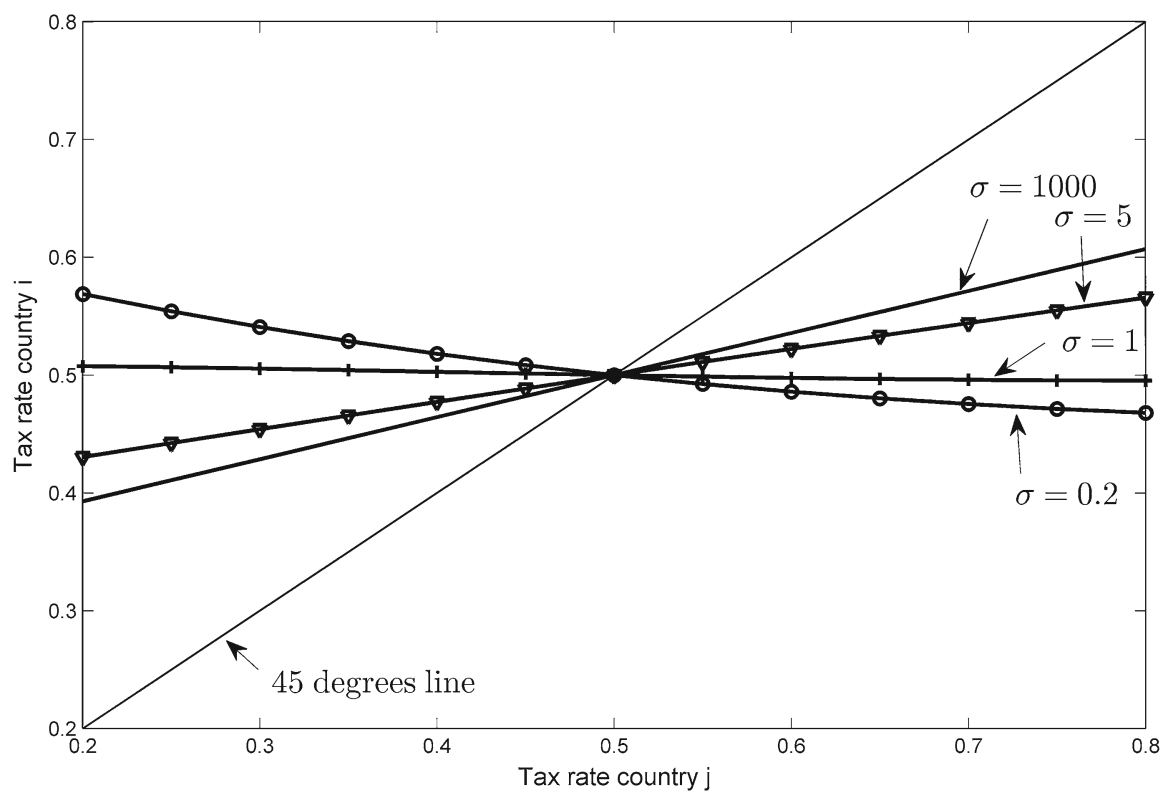

Fig. 1 Tax-reaction function country $i$ for endogenous $u_{g} / u_{c}$

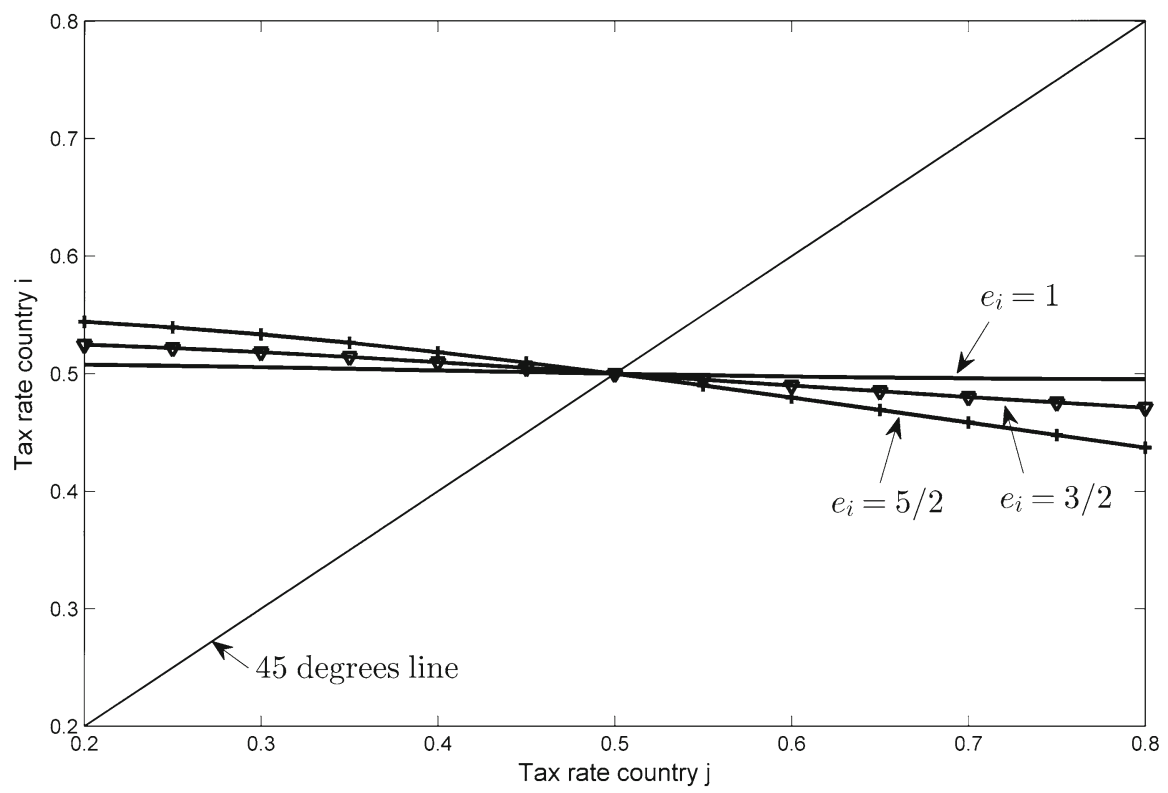

Fig. 2 Tax-reaction function country $i$ under asymmetric capital positions $e_{i} \neq k_{i}$

tax-reaction function is downward sloping but rather flat. For lower values of $\sigma$, the slope becomes more negative.

Figure 2 sets $\sigma=1$ (and $a=3.5$ to ensure $u_{g} / u_{c}=3 / 2$ ), and varies the capital endowment of country i: $e_{i} \in\{1,3 / 2,5 / 2\}$. The larger its capital endowment, the 
larger is the capital export of the country. Because countries are asymmetric in Fig. 2 , the Nash-equilibrium can no longer be found at the intersection with the $45^{\circ}$ line. The remaining parameters imply that for $e_{i}=1$, we have $M C F=3 / 2$. Note that in this case $\hat{\sigma}=1$ while $\check{\sigma}=6$ when evaluated at $e_{i}=1$. Consistent with Proposition 3 , Fig. 2 shows that the slope of the tax-reaction function becomes more negative when country 3 exports more capital.

\section{Application: coalition formation in capital taxation}

Tax-reaction functions are important for the analysis of tax competition. From a policy perspective, the slope of the tax-reaction function is also critical when studying the welfare effects of a partial tax union (see Konrad and Schjelderup 1999). This section performs simulations of the welfare effects when a subgroup of countries forms a tax union. ${ }^{16}$

In the simulations, we mainly use the three-country version of the model and adopt the same calibration as in the previous section. A final set of simulations addresses the case of more countries. In analyzing a partial tax union for $n=3$, we let countries 1 and 2 coordinate (or harmonize) the tax on capital and form a tax union (henceforth: the union countries, for which we use subscript " $h$ "). Country 3 remains outside the union (the outsider for which we use subscript " $o$ "). In case we study more than 3 countries, we let $m$ countries coordinate their capital tax whereas $n-m$ countries choose their capital tax independently. For notational simplicity, we assume that the first $m$ countries coordinate their taxes, whereas country $m+1$ till $n$ are outsiders. The union countries are assumed symmetric throughout the analysis, where $s \equiv s_{1}=s_{2}=\ldots=s_{m}$ denotes their share in the world population. The union countries choose a joint tax rate $t_{h}$ that maximizes the sum of welfare in the $m$ union countries: $\sum_{i=1}^{m} s U_{i}()=$. $m s U_{h}($.$) , given the tax rate chosen by the outsider(s). { }^{17}$ The outsider countries are assumed to be symmetric as well, where $s_{o} \equiv(1-m s) /(n-m)$. Governments of outsider countries each choose their own $t_{o}$ to maximize the welfare of their citizens, given the tax rates of both the union countries and the other outsider countries (if any). We allow the outsider countries to be either smaller or larger than the union countries in terms of population. Furthermore, we allow the outsider countries to have a larger capital endowment in order to illustrate Proposition 3. Finally, in the last case studied, we choose country size and capital holdings for the insiders such that the formation of a union resembles roughly EU capital tax coordination. Preferences are the same in all countries.

\footnotetext{
16 The welfare effects of tax unions are related to the literature on coalition formation. See e.g. Burbidge et al. (1997) who study the endogenous formation of coalitions. The authors find that cooperation between all countries is only feasible when countries are sufficiently similar such that their policy preferences are aligned. Otherwise, smaller coalitions will be formed consisting of countries with relatively similar policy preferences. This finding is confirmed by Sørensen (1996). See De Mooij and Vrijburg (2010) and the references therein for future discussion.

17 Assuming symmetry between the union countries implies that we side-step the complications that arise in case of a union between asymmetric countries. When union members are asymmetric, both their preference for the optimal union policy and the payoff from cooperation might differ. Our approach is similar to that used in the literature on coalitions, see for example Kennan and Riezman (1990).
} 
In exploring the impact of a tax union on tax rates and welfare, we compare the decentralized equilibrium (indicated by superscript " $D$ "), where all three countries choose their tax rate independently in a Nash-setting, with the equilibrium where some countries have formed a tax union (indicated by superscript " $H$ ").

\subsection{Predictions}

We first explore comparative statics to understand how a tax union affects tax rates. For the union countries, the parameters $\eta_{k, h}^{D}$ and $\eta_{r, h}^{D}$ change through the formation of a tax union. This will affect the optimal choices regarding tax rates and, therefore, outcomes. For outsider countries, there is no direct impact of a tax union. Indeed, the parameters $\eta_{k, o}^{D}$ and $\eta_{r, o}^{D}$ do not change due to the formation of a tax union. The outsider countries are, however, affected indirectly through a change in tax policy in the union countries to the extent that this modifies the allocation of capital $k_{o}$ and the interest rate $\rho$.

Section D in the online Appendix derives the tax coefficients under a tax union and finds that $\eta_{k, h}^{H}<\eta_{k, h}^{D}$ : the joint policy response by the union countries eliminates spillovers upon each other. Accordingly, when evaluated at the decentralized equilibrium values of $t_{i}$ and $k_{i}$, the formation of a tax union will generally reduce the MCF. This gives the union countries an incentive to raise their tax rate. Furthermore, Section D in the online Appendix also shows that $\eta_{r, h}^{H}=m \eta_{r, h}^{D}$. As the union countries together are $m$ times the size of a single country, the interest rate response to the tax is $m$ times as large. This larger tax coefficient of the interest rate further reduces the MCF if the union countries are net capital importers. However, a larger interest coefficient mitigates the reduction in the MCF when union countries are net capital exporters, and could in principle even dominate the reduction in $\eta_{k, h}$.

Following Konrad and Schjelderup (1999, p. 161), we derive the marginal change in welfare for the union countries in response to a marginal increase in the joint tax rate ${ }^{18}$

$$
\left.\frac{\partial U_{h}}{\partial t_{h}} \frac{1}{u_{c, h}}\right|_{t_{h}=t_{1}^{D}}=\left[\left(k_{h}-e_{h}\right)+\frac{\left(u_{g, h} / u_{c, h}\right) t_{h}}{2 b}\right]\left[(m-1) s+(1-m s) \frac{\partial t_{o}}{\partial t_{h}}\right]
$$

where we use: $\eta_{r, i}=s_{i}$ (under a quadratic production function). The first term in square brackets is unambiguously positive if the union countries are capital importers $\left(k_{h}>e_{h}\right)$. The higher tax raises welfare, both due to an increase in public consumption and due to the reduction in the interest rate. If the union countries are net capital exporters, however, the latter effect is negative as the higher tax lowers net interest income received from abroad.

The term in the second square brackets in Eq. (16) captures, following Beaudry et al. (2000), spillovers within the tax union [first term: $(m-1) s]$ and spillovers between the tax union and the outsider(s) [second term: $\left.(1-m s) \partial t_{o} / \partial t_{h}\right]$. The slope of the tax-reaction function determines the sign of the latter term, implying that the whole

\footnotetext{
18 Note, this term only includes the impact from a change in the tax rate of other union countries and outsiders. The marginal increase in the own tax rate has no impact on welfare at the margin when the initial tax rate maximizes decentralized welfare.
} 
term in the second square brackets is always positive under strategic complementarity as the outside country will adopt a tax response of the same sign as that chosen by the union countries. This is the case in Konrad and Schjelderup (1999). However, the term may become negative under strategic substitutability, in which case a welfare loss from the formation of a tax union might occur: "partial cooperation is likely to worsen welfare when spillovers within and between coalitions differ in sign and when the aggregate effects of spillovers between coalitions more than offset the positive effects from internalizing spillovers within groups (Beaudry et al. 2000, p. 10)'. Our model extends the analyses by Beaudry et al. (2000) and Konrad and Schjelderup (1999). Spillovers in Beaudry et al. are defined in a model where symmetric coalitions choose policies simultaneously, causing strategic actions (in our terminology) to be characterized by: $d t_{h} / d t_{o}=1$ when comparing the equilibrium tax policies before and after coalition formation (where we interpret the outsiders as another coalition for simplicity). Equation (16) shows that in such a hypothetical symmetric equilibrium our model will show positive spillovers within and between coalitions, ruling out welfare losses. However, in our paper outsiders do not form a coalition, such that the change in tax policy abroad only reflects a response to the creation of a tax union, whereas in Beaudry et al. $d t_{h} / d t_{o}=1$ reflects symmetric internalized spillovers only. Although the spillovers within the tax union are unambiguously positive in our model, this asymmetry in coalition formation might cause the net-of-strategicresponse-spillovers between the union and the outsider(s) to be negative. In general this occurs when: $\partial t_{o} / \partial t_{h}<-(m-1) s /(1-m s) .{ }^{19}$

The change in welfare in an outsider country is given by

$$
\left.\frac{\partial U_{o}}{\partial t_{h}} \frac{1}{u_{c, o}}\right|_{t_{o}=t_{o}^{D}}=\left[\left(k_{o}-e_{o}\right)+\frac{\left(u_{g, o} / u_{c, o}\right) t_{o}}{2 b}\right] m s .
$$

Welfare in outsider countries rises if the tax union increases its tax rate, as it benefits from an inflow of capital. Only when the outsider countries are large capital exporters, may a reduction in net interest income imply that welfare decreases.

\subsection{Simulations}

Table 1 presents simulation results of the formation of tax unions under alternative parameter values. The calibration follows Sect. 4, whereby the first five columns in the table indicate how the parameters are varied. In particular, for the $n=3$ case we consider several combinations using two values for the MRS $(3 / 2$ and 3 , the latter implying a low $\bar{\sigma})$, two values for $\sigma(1$ and 0.2$)$, and three values for the size of the countries that form a tax union $(s=2 / 5,1 / 3$ and $1 / 6)$. Furthermore, we allow country 3 to have a relatively large capital endowment in half of the simulations:

\footnotetext{
19 In case of 3 symmetric countries of which 2 form a tax union $(m=2)$, we need $\partial t_{0} / \partial t_{h}<-1$ for union countries to experience a welfare loss from marginally increasing their tax rate. We exclude this case by assuming that '... the derivatives of the reaction functions [are] less than 1 in absolute value over the relevant range ... [which] is sufficient for uniqueness [Tirole (1988), p. 226]'. See Wilson (1991, p.436) for the same assumption.
} 
$e_{3}=1 /(1-2 s)-2 s /(1-2 s) e_{h}$, affecting its capital exports. We then increase the number of countries from 3 to 12 and 210 (close to the number of countries in the world), while varying the relative size of the union (between $1 / 3$ and $2 / 3$ of all countries). This illustrates that strategic substitutes can also occur for $n$ larger than 3. For the latter simulations, we choose a value of 2 for the MRS, to ensure that the interest rate remains positive. The final row is calibrated such as to approach tax coordination within the EU, while recognizing that the model is too stylized to draw firm conclusions. For this, we used OECD-data showing that the EU inhabits currently close to $7 \%$ of the world's population and earns $25 \%$ of the world's income, which we interpret as approximately a $25 \%$ capital endowment (most likely underestimating the true figure), making the EU a large capital exporter.

Columns (6) and (7) show the decentralized equilibrium tax rates. The symmetric equilibrium is calibrated at $t=0.5$. We see that larger countries set higher tax rates, as in Bucovetsky (1991) and Wilson (1991). Furthermore, as discussed in Sect. 3, a larger capital endowment has an ambiguous effect on the equilibrium tax rate. The simulations show that when $\mathrm{MCF}=3$, the country with the larger capital endowment, country 3 , chooses a higher tax rate compared to the country with the smaller capital endowment. These results are in line with Sect. 3 , where for $\mathrm{MCF}=3$ we find $\hat{\sigma}>$ $1 \geq \sigma:$ the increase in the $M R S$ dominates the increase in the MCF that follows from a larger capital endowment. Hence, equilibrium taxes for the capital abundant country are expected to increase. For $\mathrm{MCF}=3 / 2$, equilibrium taxes are rather insensitive to changes in the capital endowment.

Column (8) shows the percentage change in the equilibrium tax rates by countries that form a tax union. We see that, except for the last row, the union countries always increase their tax rates $\left(t_{h}^{H}>t_{h}^{D}\right)$ after forming a tax union. The tax increase by the union countries is increasing in their size. Intuitively, spillovers between two larger countries are large, relative to spillovers vis-a-vis a small third country. When union countries import capital $\left(e_{h}<1\right)$, the tax increase is also generally larger, since the resulting lower interest rate benefits net capital importers at the expense of capital exporters. Furthermore, we see that when the union becomes a small fraction of the total number of countries (from $2 / 3$ to $1 / 3$ ), the increase in the tax by the union countries is reduced because the internalized spillovers are relatively smaller. The reduction in the equilibrium tax rate after the formation of a union in the last row can be explained by pointing out that the EU is a large capital exporter, hence, lower taxes raise net interest income in the EU.

Column (9) shows that the response by the non-union country varies, reflecting either strategic complementarity or strategic substitutability. In fact, outsider countries reduce their tax rate in most cases reported in Table 1 consistent with strategic substitutability. Hence, strategic substitutability might be a reasonable case in tax competition models when governments maximize welfare. If union countries increase their tax rate by more, we see that also the change by the outsider countries gets larger. The opposite holds if the union becomes a smaller fraction of the total number of countries.

The last two columns present the welfare effects measured by the compensating variation $(C V)$ as a percentage of total production of a country: $f\left(k_{i}\right)=\left(a-b k_{i}\right) k_{i}$. The $C V_{i}$ represents the increase in private consumption that is required under the tax 
Table 1 Simulation results

\begin{tabular}{|c|c|c|c|c|c|c|c|c|c|c|}
\hline (1) & $(2)$ & (3) & (4) & (5) & (6) & (7) & (8) & (9) & (10) & (11) \\
\hline$\frac{u_{g}}{u_{c}}$ & $\sigma$ & $s$ & $e_{h}$ & $n(\mathrm{~m})$ & $t_{h}^{D}$ & $t_{o}^{D}$ & $\Delta t_{h} / t_{h}(\%)$ & $\Delta t_{o} / t_{o}(\%)$ & $C V_{h}(\%)$ & $C V_{o}(\%)$ \\
\hline $3 / 2$ & 1 & $2 / 5$ & 1 & $3(2)$ & 0.51 & 0.48 & 14.59 & -0.45 & -0.75 & -3.63 \\
\hline $3 / 2$ & 1 & $2 / 5$ & $3 / 4$ & $3(2)$ & 0.52 & 0.50 & 22.71 & -4.53 & -1.15 & 0.23 \\
\hline $3 / 2$ & 1 & $1 / 3$ & 1 & $3(2)$ & 0.50 & 0.50 & 12.25 & -0.30 & -0.52 & -2.43 \\
\hline $3 / 2$ & 1 & $1 / 3$ & $3 / 4$ & $3(2)$ & 0.50 & 0.50 & 18.31 & -1.84 & -0.78 & -1.77 \\
\hline $3 / 2$ & 1 & $1 / 6$ & 1 & $3(2)$ & 0.47 & 0.56 & 6.13 & -0.06 & -0.13 & -0.53 \\
\hline $3 / 2$ & 1 & $1 / 6$ & $3 / 4$ & $3(2)$ & 0.46 & 0.55 & 8.40 & -0.18 & -0.19 & -0.63 \\
\hline $3 / 2$ & $1 / 5$ & $2 / 5$ & 1 & $3(2)$ & 0.50 & 0.49 & 2.73 & -0.51 & -0.14 & -0.83 \\
\hline $3 / 2$ & $1 / 5$ & $2 / 5$ & $3 / 4$ & $3(2)$ & 0.50 & 0.50 & 4.44 & -2.38 & -0.15 & 0.02 \\
\hline $3 / 2$ & $1 / 5$ & $1 / 3$ & 1 & $3(2)$ & 0.50 & 0.50 & 2.48 & -0.39 & -0.09 & -0.58 \\
\hline $3 / 2$ & $1 / 5$ & $1 / 3$ & $3 / 4$ & $3(2)$ & 0.50 & 0.50 & 3.84 & -1.15 & -0.10 & -0.45 \\
\hline $3 / 2$ & $1 / 5$ & $1 / 6$ & 1 & $3(2)$ & 0.49 & 0.51 & 1.52 & -0.11 & -0.02 & -0.15 \\
\hline $3 / 2$ & $1 / 5$ & $1 / 6$ & $3 / 4$ & $3(2)$ & 0.49 & 0.51 & 2.10 & -0.19 & -0.02 & -0.18 \\
\hline 3 & 1 & $2 / 5$ & 1 & $3(2)$ & 0.53 & 0.46 & 50.75 & 8.94 & -6.76 & -22.30 \\
\hline 3 & 1 & $2 / 5$ & $3 / 4$ & $3(2)$ & 0.51 & 0.50 & 56.31 & 13.50 & -6.45 & -33.02 \\
\hline 3 & 1 & $1 / 3$ & 1 & $3(2)$ & 0.50 & 0.50 & 35.98 & 6.41 & -4.94 & -15.01 \\
\hline 3 & 1 & $1 / 3$ & $3 / 4$ & $3(2)$ & 0.48 & 0.52 & 39.40 & 8.12 & -4.66 & -20.14 \\
\hline 3 & 1 & $1 / 6$ & 1 & $3(2)$ & 0.47 & 0.67 & 12.19 & 1.05 & -0.99 & -3.08 \\
\hline 3 & 1 & $1 / 6$ & $3 / 4$ & $3(2)$ & 0.45 & 0.67 & 13.39 & 1.14 & -0.96 & -3.53 \\
\hline 3 & $1 / 5$ & $2 / 5$ & 1 & $3(2)$ & 0.51 & 0.48 & 8.72 & -1.50 & -1.18 & -7.02 \\
\hline 3 & $1 / 5$ & $2 / 5$ & $3 / 4$ & $3(2)$ & 0.47 & 0.54 & 9.15 & 2.18 & -1.32 & -28.01 \\
\hline 3 & $1 / 5$ & $1 / 3$ & 1 & $3(2)$ & 0.50 & 0.50 & 8.76 & -1.72 & -0.82 & -5.69 \\
\hline 3 & $1 / 5$ & $1 / 3$ & $3 / 4$ & $3(2)$ & 0.46 & 0.56 & 8.36 & -0.44 & -0.75 & -12.24 \\
\hline 3 & $1 / 5$ & $1 / 6$ & 1 & $3(2)$ & 0.47 & 0.55 & 5.10 & -0.73 & 0.14 & -1.25 \\
\hline 3 & $1 / 5$ & $1 / 6$ & $3 / 4$ & $3(2)$ & 0.43 & 0.57 & 4.46 & -0.66 & 0.15 & -1.21 \\
\hline 2 & $1 / 5$ & $1 / 12$ & 1 & $12(8)$ & 0.50 & 0.50 & 5.43 & -0.37 & -0.33 & -1.44 \\
\hline 2 & $1 / 5$ & $1 / 12$ & 1 & $12(4)$ & 0.50 & 0.50 & 10.09 & -1.48 & -1.46 & -4.80 \\
\hline 2 & $1 / 5$ & $1 / 210$ & 1 & $210(140)$ & 0.50 & 0.50 & 5.84 & -0.84 & -0.58 & -1.59 \\
\hline 2 & $1 / 5$ & $1 / 210$ & 1 & $210(30)$ & 0.50 & 0.50 & 1.57 & -0.04 & -0.03 & -0.09 \\
\hline 2 & $1 / 5$ & $7 / 100 \quad 1 / 30$ & 3.6 & $210(30)$ & 0.60 & 0.49 & -0.56 & 0.01 & -0.01 & 0.02 \\
\hline
\end{tabular}

For all simulations, we choose $\omega=1 / 2$. The parameter $b$ in the production function $f=b(a-k) k$, is calibrated on the symmetric equilibrium, using $t=1 / 2$, such that $b$ follows from the choice of $u_{g} / u_{c}=$ MCF. $a$ follows from the choice of $\sigma$ such that the MRS equals the desired value of $u_{g} / u_{c}$. See Sect. 4 for a discussion. With respect to $\check{\sigma}$ we find in case of the 3-country simulations: (i) for $\mathrm{MCF}=3 / 2$ and $\sigma=1, \check{\sigma}>5.75$; (ii) for $\mathrm{MCF}=3 / 2$ and $\sigma=0.2$; (iii) $\check{\sigma}>8$; (iv) for $\mathrm{MCF}=3$ and $\sigma=1, \check{\sigma}>1.4$; (v) and for $\mathrm{MCF}=3$ and $\sigma=0.2, \check{\sigma}>3.4$. For $n=12, \check{\sigma}>14$ and for $n=210, \check{\sigma}>300$

union equilibrium to make the citizens of country $i$ equally well off as compared to the decentralized equilibrium. A negative value therefore indicates a welfare gain from the formation of a tax union; a positive value reflects a welfare loss. We see that in most cases both countries gain from the formation of a tax union. This gain is bigger 
when large countries form a tax union and when tax rates are strategic complements. The outsider country only loses from the tax union when it is a capital exporter. The union countries suffer a welfare loss when (i) the union countries are small compared to the non-union country; and (ii) the outsider country responds to the tax increase by the union countries by reducing its own tax rate. ${ }^{20}$ In the calibration for the EU, we see a small welfare gain for the EU countries upon forming a tax union and a small welfare loss for the remaining countries.

The above results imply the following lessons for the literature on tax coordination. First, we extend Beaudry et al. (2000) by showing that the welfare effects of partial tax unions should be judged inclusive of strategic responses between the tax union and outsiders. Our model features positive spillovers within the tax union and between the tax union and outsiders when evaluated exclusive of strategic responses. Yet, we show that strategic substitutability can turn the sign of the latter spillover, which might dominate the welfare effect of a partial tax union. This implies that if the EU is seen as a relatively closed economy, studies on tax coordination among a subset of EU member states should incorporate strategic effects which might reduce the welfare gains. Indeed, Brøchner et al. (2007) and Bettendorf et al. (2010) may overestimate the welfare gains from a tax union. In contrast,Sørensen (2004a) does allow for strategic responses. Second, papers that study tax coordination amongst all EU member states often ignore strategic reactions upon the creation of such a tax union (see e.g. Bettendorf et al. 2006; Sørensen 2004b; Brøchner et al. 2007). Our simulations suggest that relaxing this assumption might not affect the key results of these papers much. Both the large number of countries outside the EU and the endogenous marginal valuation of public goods (causing relative flat reaction functions) cause small strategic responses in that case. Furthermore, these papers often assume that the EU member states will coordinate upon an effective tax rate close to the current EU average. This may be close to the upper-bound of the range of reasonable long-run coordinated equilibrium tax rates for the EU, given that the EU is a large capital exporter.

\section{Conclusion}

This paper analytically derives the conditions for tax rates to be strategic substitutes in an asymmetric tax-competition model. These conditions appear to be rather mild as long as governments maximize welfare and utility is generally specified. Specifically, under reasonable parameter values a substitution elasticity between public and private goods below unity is sufficient to cause tax rates to be strategic substitutes in the standard tax competition model with symmetric countries. With asymmetric countries, a downward sloping tax-reaction function is more likely to occur for capital exporters.

The existence of strategic substitutes has important implications for the welfare effects of tax unions. For instance, earlier papers either explicitly or implicity assumed that tax rates are strategic complements and found that the formation of tax unions is

\footnotetext{
20 A welfare loss for the countries that form a tax union can be avoided when assuming a Stackelbergleader game, where the union countries act as the Stackelberg leader. In this case, strategic substitutes still leads to a welfare loss, but now all is on account of outsider countries, as the union countries foresee the "aggressive" response by the outsiders (see De Mooij and Vrijburg 2010 for a discussion).
} 
unambiguously welfare improving for the participating countries. In the presence of strategic substitutes, however, we show that the formation of a tax union might actually reduce welfare for the union countries since the adverse response in the outside country may offset the benefits of forming the union.

Our paper leaves room for several extensions. First, one may want to allow for a more general class of government objectives, including the Leviathan government, as in Edwards and Keen (1996). Second, endogenous coalition formation along the lines of Kempf and Rota-Graziosi (2010) may shed new light on strategic tax interactions. Which tax unions will be formed, and how this is related to the existence of strategic substitutes is left for future research.

Acknowledgments The authors thank Leon Bettendorf, Aart Gerritsen, Andreas Haufler, Bas Jacobs, Joana Pereira, Floris Zoutman and two anonymous referees for helpful comments.

\section{Appendix: Deriving tax coefficients}

This appendix derives the tax coefficients $\eta_{k, i}$ and $\eta_{r, i}$ defined in Eqs. (3) and (4) in Sect. 2.1.

Decentralization

Under decentralization, we first differentiate Eq. (1) to show how a change in the tax rate in country $i$ affects the capital stock in countries $i$ and $j$

$$
\begin{aligned}
\frac{\partial k_{i}}{\partial t_{i}} & =\frac{1}{f_{i}^{\prime \prime}(.)}\left[1+\frac{\partial \rho}{\partial t_{i}}\right], \\
\frac{\partial k_{j}}{\partial t_{i}} & =\frac{1}{f_{j}^{\prime \prime}(.)}\left[\frac{\partial \rho}{\partial t_{i}}\right] \text { for } j \neq i .
\end{aligned}
$$

From Eq. (2) it follows that the total size of the capital stock is fixed, therefore

$$
s_{i} \frac{\partial k_{i}}{\partial t_{i}}=-\sum_{j=1, j \neq i}^{n} s_{j} \frac{\partial k_{j}}{\partial t_{i}}
$$

Combining Eqs. (17)-(19) we obtain

$$
0>\frac{\partial \rho}{\partial t_{i}}=\frac{-s_{i} / f_{i}^{\prime \prime}(.)}{\sum_{j=1}^{n} s_{j} / f_{j}^{\prime \prime}(.)} \equiv-\eta_{r, i}^{D}>-1,
$$

filling this in Eq. (17) gives

$$
\frac{\partial k_{i}}{\partial t_{i}}=\frac{1}{f_{i}^{\prime \prime}(.)}\left\{\frac{\sum_{j=1, j \neq i}^{n}\left[s_{j} / f_{j}^{\prime \prime}(.)\right]}{\sum_{j=1}^{n}\left[s_{j} / f_{j}^{\prime \prime}(.)\right]}\right\} \equiv-\eta_{k, i}^{D}<0 .
$$




\section{References}

Bayindir-Upmann, T., \& Ziad, A. (2005). Existence of equilibria in a basic tax-competition model. Regional Science and Urban Economics, 35, 1-22.

Beaudry, P., Cahuc, P., \& Kempf, H. (2000). Is it harmful to allow partial cooperation? Scandinavian Journal of Economics, 95, 1-21.

Bettendorf, L., Gorter, J., \& van der Horst, A. (2006). Who benefits from tax competition in the European Union? CPB Document 125, CPB Netherlands Bureau for Economic Policy Analysis.

Bettendorf, L., van der Horst, A., de Mooij, R. A., \& Vrijburg, H. (2010). Corporate tax consolidation and enhanced cooperation in the European Union. Fiscal Studies, 31, 453-479.

Brøchner, J., Jensen, J., Svensson, P., \& Sørensen, P. B. (2007). The dilemmas of tax coordination in the enlarged European Union. CESifo Economic Studies, 53, 561-595.

Brueckner, J. K. (2003). Strategic interaction among governments: An overview of empirical studies. International Regional Science Review, 26, 175-188.

Brueckner, J. K., \& Saavedra, L. A. (2001). Do local governments engage in strategic property-tax competition? National Tax Journal, 54, 203-230.

Bucovetsky, S. (1991). Asymmetric tax competition. Journal of Urban Econonomics, 30, 167-181.

Bucovetsky, S. (2009). An index of capital tax competition. International Tax and Public Finance, 16, $727-752$.

Bucovetsky, S., \& Wilson, J. D. (1991). Tax competition with two tax instruments. Regional Science and Urban Economics, 21, 333-350.

Bulow, J. I., Geanakoplos, J. D., \& Klemperer, P. D. (1985). Multimarket oligopoly: Strategic substitutes and complements. The Journal of Political Economy, 93, 488-511.

Burbidge, J. B., DePater, J. A., Myers, G. M., \& Sengupta, A. (1997). A coalition-formation approach to equilibrium federations and trading blocs. The American Economic Review, 87, 940-956.

Case, A. C., Rosen, H. S., \& Hines, J. R. (1993). Budget spillovers and fiscal policy interdependence. Journal of Public Economics, 52, 285-307.

Chirinko, R.S., \& Wilson, D.J. (2011). Tax Competition Among US states: Racing to the Bottom or Riding on a Seesaw? CESifo Working paper No. 3535, CESifo.

De Mooij, R.A., \& Vrijburg, H. (2010). Enhanced cooperation in an asymmetric model of tax competition. CESifo Working paper No. 2915, CESifo, Munich.

Devereux, M., Lockwood, B., \& Redoano, M. (2008). Do countries compete over corporate tax rates? Journal of Public Economics, 92, 1210-1235.

Edwards, J., \& Keen, M. (1996). Tax competition and the Leviathan. European Economic Review, 40, $113-134$.

Egger, P., Pfaffermayr, M., \& Winner, H. (2005a). Commodity taxation in a 'linear' world: A spatial panel data approach. Regional Science and Urban Economics, 35, 527-541.

Egger, P., Pfaffermayr, M., \& Winner, H. (2005b). An unbalanced spatial panel data approach to US state tax competition. Economics Letters, 88, 329-335.

Houthakker, H. S. (1960). Additive preferences. Econometrica, 28, 244-257.

Jacobs, J. P. A. M., Ligthart, J. E., \& Vrijburg, H. (2010). Consumption tax competition among governments: Evidence from the United States. International Tax and Public Finance, 17, 271-291.

Kanbur, R., \& Keen, M. (1993). Jeux Sans Frontieres: Tax competition and tax coordination when countries differ in size. American Economic Review, 83, 877-892.

Kempf, H., \& Rota-Graziosi, G. (2010). Endogenizing leadership in tax competition. Journal of Public Economics, 94, 768-776.

Kennan, J., \& Riezman, R. (1990). Optimal tariff equilibria with customs unions. The Canadian Journal of Economics, 23, 70-83.

Konrad, K. A., \& Schjelderup, G. (1999). Fortress building in global tax competition. Journal of Urban Economics, 46, 156-167.

Laussel, D., \& Le Breton, M. (1998). Existence of Nash equilibria in fiscal competition models. Regional Science and Urban Economics, 28, 283-296.

Leibrecht, M., \& Hochgatterer, C. (2012). Tax competition as a cause of falling corporate income tax rates: A survey of empirical literature. Journal of Economic Surveys, 26, 616-648.

Lockwood, B. (2004). Competition in unit vs. ad valorem taxes. International Tax and Public Finance, 11, 763-772. 
Mintz, J., \& Tulkens, H. (1986). Commodity tax competition between member states of a federation: Equilibrium and efficiency. Journal of Public Economics, 29, 133-172.

Overesch, M., \& Rincke, J. (2011). What drives corporate tax rates down? A reassessment of globalization, tax competition, and dynamic adjustment to shocks. Scandinavian Journal of Economics, 113, 579602.

Parchet, R. (2013). Are local tax rates strategic complements or strategic substitutes. Mimeo: University of Lausanne.

Parry, I. (2003). How large are the welfare costs of tax competition? Journal of Urban Economics, 54, 39-60.

Peralta, S., \& van Ypersele, T. (2005). Factor endowments and welfare levels in an asymmetric tax competition game. Journal of Urban Economics, 57, 258-274.

Peralta, S., \& van Ypersele, T. (2006). Coordination of capital taxation among asymmetric countries. Regional Science and Urban Economics, 36, 708-726.

Rubinfeld, D. L. (1987). The economics of the local public sector. In A. Auerbach \& M. Feldstein (Eds.), Handbook of public economics (Vol. 2, pp. 571-645). Amsterdam: Elsevier, North-Holland.

Sørensen, J. R. (1996). Coordination of fiscal policy among a subset of countries. The Scandinavian Journal of Economics, 98, 111-118.

Sørensen, P. B. (2004a). International tax coordination: Regionalism versus globalism. Journal of Public Economics, 88, 1187-1214.

Sørensen, P. B. (2004b). Company tax reform in the European Union. International Tax and Public Finance, $11,91-115$.

Taugourdeau, E., \& Ziad, A. (2011). On the existence of Nash equilibria in an asymmetric tax competition game. Regional Science and Urban Economics, 41, 439-445.

Tirole, J. (1988). The theory of industrial organization. Cambridge, Massachusetts: MIT Press.

Wildasin, D. E. (1989). Interjurisdictional capital mobility: Fiscal externality and a corrective subsidy. Journal of Urban Economics, 25, 191-212.

Wilson, J. D. (1986). A theory of interregional tax competition. Journal of Urban Economics, 19, $296-315$.

Wilson, J. D. (1991). Tax competition with interregional differences in factor endownments. Regional Science and Urban Economics, 21, 423-451.

Zodrow, G. R., \& Mieszkowski, P. (1986). Pigou, Tiebout, property taxation and the underprovision of local public goods. Journal of Urban Economics, 19, 356-370. 